\title{
Introduction to Equity and Digital Literacies: Access, Ethics, and Engagements
}

\author{
THERESA ROGERS \\ University of British Columbia \\ SUZANNE SMYTHE \\ Simon Fraser University \\ RON DARVIN \\ University of British Columbia \\ JIM ANDERSON \\ University of British Columbia
}

This special issue arises out of a unique, jointly-sponsored conference held at the University of British Columbia Faculty of Education in the spring of 2016. The Equity in Digital Literacies conference brought together international scholars, Canadian scholars, and local community educators to address issues of (in)equities of digital literacies in homes, schools, and communities locally and across the world. As researchers at UBC and Simon Fraser University, we wanted to identify ways that educators are and should be responsive to the various constraints as well as the possibilities for engaging people in meaningful digital language and literacy practices.

Many educational researchers who have focused on digital language and literacy practices perceive them to be more democratic (Dobson \& Willinsky, 2009) and to foster more participatory, collaborative, and distributed engagements (e.g., Ito et al., 2009; Jenkins, Clinton, Purushotma, Robison, \& Weigel, 2009; Knobel \& Lankshear, 2006; Rowsell \& Pahl, 2007). However, given that the phenomenon of digital practices occurs in broader social, political, and economic contexts, a more critical model of digital literacy (Warschauer, 2009) allows us to examine both the modes of inclusion and exclusion shaped by digital technologies. As advanced capitalist countries transition to a postindustrial capitalism where material production is replaced by information processing and automation, being able to use technology has become "the critical factor in generating and accessing wealth, power, and knowledge” (Castells, 2010, p. 93). At the same time, as the fulcrum of capitalist society in the knowledge economy, technology can lead to "one of the most damaging forms of exclusion” (Castells, 2010, p. 3).

When digitization is set against this wider backdrop of society, tensions and imbalances of power inevitably surface. How one is able to access and use technology is not only dependent on one's possession of economic capital, but also contingent on government, institutions, and policies that enable such access among individuals and groups. Inequities arise from these conditions of access, and from differences in digital usage and tastes (North, Snyder, \& Bulfin, 2008; Selwyn, 2017; Snyder \& Prinsloo, 2007), valued differently across contexts, and resulting in divergent social and educational outcomes (Warschauer \& Matuchniak, 2010). 
To explore these issues in depth, particularly in relation to digital and media literacies and in particular contexts, scholars from UBC and SFU proposed a conference entitled "Equity in Digital Literacies” (see http://dlc.lled.educ.ubc.ca/2016/11/18/equityin-digital-literacies-access-ethics-engagement/ for archive). In conceptualizing the event, we asked questions such as: How do various economic, geographical, linguistic, social, ideological, structural, and ethical factors affect the way learners engage in local, translocal, and transnational digital practices? How can multimodal, multilingual, and digital literacy practices be mobilized and scaled as assets for public engagement in and beyond boundaries of schools, communities, and nations? In this new information environment, what do we need to consider with respect to power and risks, possibilities and limits, and social and material relations and inequities (i.e., regarding communicative ethics)? And, how can teachers, community educators, and students leverage increased access to knowledge as public goods and lifelong tools of political, social, and intellectual engagement?

Our four keynote speakers-John Willinsky, Eva Lam, Anabel Quan-Haase, and Allan Luke-generated rich discussions of the problems and potential for new technologies to interrupt, and to reproduce, offline orthodoxies and inequalities. For John Willinsky, digital technologies open new possibilities for more democratic knowledge creation and sharing in the academy, as well as new possibilities for public knowledge and civic literacies. Eva Lam took the discussion into private spaces, asking how new technologies play out in the intimate spaces of family life and how these spaces are reconfigured in the new publics of social media and schooling. Anabel Quan-Haase reminded us that the digital terrain in Canada is rife with inequalities in access to devices, internet connectivity, and practices, and that these inequalities must be at the forefront of plans and policies to incorporate digital pedagogies in education. Finally, Allan Luke, in closing the conference, sounded warnings about the misplaced faith in the power and promise of technologies that he has detected in education circles. He observed how our technology apparatus is vulnerable to collapse from human and nonhuman forces-asking digital scholars to orient our attention to the climatic and human tragedies unfolding around us, and to rebuild relationships with natural social worlds. Weaving through these provocative contributions were presentations of emerging research that each in their own way address and grapple with these themes; much of this work appears in this special issue.

We conceptualized and organized the conference around the themes of access, ethics, and engagement in digital literacies and, in addition to the keynote speakers, we offered panel presentations and engaged participants in small group discussions grounded in the real, everyday issues that people encounter as they navigate a more technologized world. Many of these papers and discussions focused on various partnerships with local community groups, such as education programs located in the Vancouver Downtown Eastside, the Burnaby Neighbourhood House, and the First Peoples' Cultural Council, as well as with teachers and librarians from schools in the Vancouver School District. Other manuscripts focused on broader initiatives and projects in national and global contexts.

The ten papers we selected for this issue address the multifaceted nature of equity and digital literacies as it related to race, class, language, age, gender, sexuality, indigeneity, and geopolitical forces. The papers range from research studies to reports on projects and issues of concern in particular educational contexts. The sites featured in these articles range from local Vancouver communities to Canadian and international settings, 
including countries in Africa, and China and the United States. In various ways, the authors address our initial questions about digital equity as they grapple with issues of access, ethics, and engagement among children, youth, and adults that arise in research and practice across diverse educational and community sites.

We very deliberately begin with our own local community. Vancouver is, arguably, a global city with all the attendant qualities of places that are experiencing economic inequalities, transnational mobility, immigration, loss of affordable housing, the closing down of public spaces, and other characteristics so common in these contexts. In fact, in British Columbia has the third highest rate of income inequality in Canada, where the richest $10 \%$ of BC families collect 11 times as much income as the poorest $10 \%$ (First Call, 2017). In many cases, digital spaces have become proxies for employment opportunities, social connection, and social services, yet many societal inequalities are reproduced in terms of access to services and education, ethics, and digital and social inclusion.

Section 1 of this issue includes six papers that provide a closer look at the consequences of inequities related to digital literacies for people-particular older youth and adults - in Vancouver and, by extension, in other communities. In their paper on the LinkVan project, Smythe, Pelan, and Breshears describe a participatory technology design project developed to forge more equitable digital and social relations for citizens in the Downtown Eastside (DTES) community of Vancouver who are low income or experiencing homelessness. They begin by tracing digital inequalities, with a focus on the precariousness of digital access and usability, and then describe how they directly involved 58 technology users in the design of their tool-an open source, "literacy-friendly" directory of services that responded to the particular needs of the community. Describing the emergent and improvisational nature of the participatory design process, Smythe et al. illustrate how involving marginalized technology users in the design and critique of new technologies can lead to more usable and responsive technology design. Based on their project, they raise new and provocative questions regarding the capacities of technologies to address social inequalities, as well as the ways in which discourses of scarcity pervade social and digital policy landscapes. The authors call for greater attention to technology users' imaginings of a more equitable digital and social landscape.

Drawing on a Bourdieusian conception of class, Darvin's paper examines how both material conditions at home and class positionings shape two adolescent Filipino immigrants' dispositions and engagements with out-of-school digital technology. While both participants exhibited adeptness with and passion for technology, Darvin notes, "there are striking differences when it comes to their views of what technology is for, and how they use it at home." While one privately educated, resource-rich student was "able to position himself as a global citizen"-using technology to gain as well as create information and knowledge-his public school educated, less-advantaged peer more passively received technology as a form of entertainment, thereby deriving less economic, cultural, and social capital from his digital interactions. Advocating for a reevaluation of the assumption that students of younger generations are universally equipped with uniform digital adeptness and literacy (i.e., “digital natives”), Darvin recommends that schools and teachers develop appropriate scaffolds for the "diverse digital repertoires of their students."

Robson, Gutman, Marchbank, and Blair describe a collaborative researcher/community arts-based project designed to raise public awareness of the underreported and under-researched problem of LGBT elder abuse in an effort to generate 
systemic change. Through a series of arts workshops and public speaking events, the intergenerational blend of participants designed, created, and disseminated digital materials — such as digital videos and visual media — on the realities of LGBT elder abuse across British Columbia. They provide examples of how community was fostered among LGBTQ/2S youth and elders (two populations that rarely interact) and how participants, who might otherwise be reductively labeled "at risk," were effective speakers and experts on the topic. While pointing out resource challenges and concerns regarding the digital representations of survivors of abuse (i.e., the risk of re-victimization), the lack of firsthand accounts, and the difficulty of presenting an ethnically diverse range of survivors in their materials, they emphasize how participants acquired critical content knowledge, media skills, and in the process learned a great deal about themselves and each other.

Ford's article details the continuing challenges to his role as the Media Programs Facilitator for Directions Youth Services, a program that serves youth in Vancouver who are either experiencing homelessness or are precariously housed. Initially a music program, the Media Program now includes a range of digital content and outreach. Its website, Another Slice, provides a space for youth voices to disseminate their creative projects and activities via blogs, a zine, and media uploads. Ford argues that while the program draws on arts and technology to build skills and confidence and expand modes of self-expression among youth, it is not without its ethical challenges. He grapples with how to keep technology accessible and empowering while at the same time maintain sensitivity to the youths' experiences and the unintended consequences of their access to and creation of various kinds of digital content. Specifically, he considers the ethical implications of privacy considerations and his role as a gatekeeper, facilitator, and educator of youth on responsible uses of technology (including when to apprise them of its hidden risks or shield them from specific content).

Through the lens of critical discourse analysis, Warfield examines the limited treatment of digital images of bodies shared online via social media (e.g., selfies) in a 2015 Canadian teaching resource designed for Grades 7 through 9. By first demonstrating how this resource, Put Your Best Face Forward (created by MediaSmarts), interprets and promotes the misconception that selfies belong to either representational or presentational paradigms of self-imaging, Warfield then argues for a new materialist approach to the interpretation of selfies-broadening understandings of this multifaceted "digital literacy phenomenon.” She maintains that infusing teaching resources with lessons, activities, and exercises that focus on the affective, embodied, and material nature of self-images shared online would provide more complicated and insightful readings of selfies (a development of particular importance in the Canadian context, where laws and curricular materials are increasingly attempting to address the sharing of "intimate images online”). Ultimately, she contends that imbuing educational materials with the nuanced, entangled meanings of and connections "between images and living, affective, and feeling bodies" would validate the lived experiences of students-such as those she works with in a project in Surrey, B.C.- - and engage young people in more critical reflections on and discussions concerning online/offline spaces, digital technologies and platforms, and the embodied experience of digital imaging.

The last article in this section by Henry discusses the formative stages of creating a digital oral history archive of Black communities in British Columbia. Stemming from a Black community initiative at the National Congress of Black Women Foundation 
(NCBWF) in which 59 interviews were recorded with participants ranging from 28 to 85 years old, Henry's project documents the historical and cultural experiences of African Canadians who have lived or are living in Vancouver-while expanding the ways of thinking about Blackness (i.e., racial literacy) in both B.C. and Canada as a whole. Henry draws on a number of theoretical frameworks, including "diaspora theories, critical race feminisms, biographical studies, and sociocultural theories of language" to analyze the themes of "migration, work, racism, education, family, community, identity, alienation, and activism" that consistently emerged in the initial analysis of the NCBWF taped interviews. She highlights the political, cultural, and ethical considerations and tensions involved in preparing and carrying out such a project-including those inherent in the collaboration between universities and community nonprofit organizations; her own researcher positionality and her assumed "insiderness" as a Black woman and scholar; the use of digital technologies to represent speakers' voices and intended meanings; and the physical housing of the archive itself as it relates to questions of ownership and spaces of power.

The articles in this section raise many critical issues related to digital literacies and equity. These issues include limited access to digital resources as indexical of class; particular uses of resources that lead to differential outcomes and benefits, as well as the usability of those resources; how some groups may be put at risk through particular kinds of representations via digital technologies; the importance of critical examinations of content; and the ethics of researching and educating vulnerable populations or groups with relatively less power. These issues asked of each of the researchers that they navigate complex relationships between the socially and digitally produced inequalities at play in each of their research settings and, in this moment when technologies are mobilized to nefarious and indeterminate ends (e.g., with regard to Facebook, automation, privacy), to stay alive to the ethics of digital education and engagement.

The papers in Section 2 revisit many of these concerns with new perspectives, broadening the scope of these issues with projects that are more global in scale. The first paper by Galla examines the confluence of digital technology and revitalization efforts of and by Indigenous cultures and communities. She begins by chronicling the loss of Indigenous linguistic and cultural heritage and knowledge through legislation and residential schooling - underscoring its intergenerational impact. She also describes the challenge of digital accessibility in under-resourced Indigenous communities, where (at least according to US studies) many households struggle to gain access to basic utilities. She then outlines the benefits and drawbacks to using digital technology as a tool for virtual engagement with languages and communities as part of revitalization and educational efforts. While digital technology can be viewed as a new form of colonization-with the potential to reinforce dominant worldviews and modes of knowledge, suppress, appropriate, and/or commodify Indigenous peoples and culture, and disconnect communities from their members and their land-it can also be construed as an empowering and archival educational tool, engaging Indigenous youth in the documentation and promotion of language, culture, and knowledge, and extending the reach of Indigenous voices. Galla calls for Indigenous languages themselves to be given more resources and support in all domains - to be prioritized and legitimized alongside colonial languages - while also acknowledging that some communities deliberately choose to keep their languages private. 
The next two articles focus on the advent of multilingual digital storybook archives that were initially created to increase the available literature and support literacy in African countries. Stranger-Johannessen, Doherty, and Norton examine the ways in which the digital literacy platform African Storybooks and its ongoing sister research project, Storybooks Canada-part of the expanding digital network of Open Educational Resources (OER)—support equitable, multilingual literacy education and teaching practices by providing widespread access to print/audio versions of local and global stories at little to no cost. They argue that these resources allow readers, families, and teachers to access multiple translations of individual stories, facilitating multilingual reading engagement and, particularly in African countries, expanding the number of stories available in both local and global languages on various platforms.

Turning to Storybooks Canada, the authors contend that introducing African stories to the Canadian audience in the most commonly spoken languages disrupts traditional global knowledge flows, thereby democratizing international knowledge by transferring stories from the Global South to the Global North. Among the benefits noted include the use of these stories in Canadian classrooms to teach foreign languages, as well as the range of opportunities provided for users to engage with story. They conclude by outlining plans for a pilot classroom study to refine the efficacy of Storybooks Canada in promoting literacy and language learning among heritage language speakers, immigrants, and refugees in Canada.

Dobson and Asselin engage in a critical discussion of digital text production and literacy programs designed to mitigate the perceived "crisis" of low literacy rates in majority world contexts, noting how such interventions-rooted in the presumption that Western models of literacy education are vital worldwide-have the damaging potential to maintain hegemonic structures that lead to social, political, and cultural disenfranchisement. Focusing on Ethiopia's long and venerated tradition of scholarly and liturgical book and manuscript production, they detail the comparative dearth of written texts produced for children. Stories for children are instead primarily conveyed through oral traditions within communities and families. Such narratives are intrinsically authentic to children's everyday experiences and linguistic backgrounds, as well as performative in nature - features that are difficult to transmediate into written and visual form. Noting that primary school children in Ethiopia have the right to be taught in their mother tongue, they describe how, due to the lack of reading materials, multilingual teachers, and funding to provide sufficient translations, this remains a difficult task to implement. The authors then turn to their discussion of literacy projects (i.e., template-driven production approaches, crowdsourcing, open licences, and versioning programs) designed to draw on students' funds of knowledge through culturally relevant texts. They consider three such digital corpora-ultimately questioning these programs' dedication to cultural authenticity and problematizing the prioritization of quick and low-cost efforts to engage oral literacy contexts with Western models of knowledge production.

The final paper by Li, Jee, and Sun addresses the implications of teacher-controlled educational technology in English as a Foreign Language (EFL) classrooms-specifically by examining the effects of technology-assisted instruction on communicative practices in suburban/rural classrooms in China. Rather than enhance meaningful teacher-student interactions or contribute to student-centered learning, teacher-controlled technology use in EFL classrooms emerges here as an impediment to students' authentic, spontaneous 
language output in the target language. By reinforcing traditional, teacher-centered instruction, such technology use restricts the types of feedback provided to students and, by extension, limits opportunities for diverse and authentic student responses. The authors call for further research into the professional development strategies and resources being provided to educators in these areas, particularly in those rural communities wherein teachers face considerable pressure to keep up with the national curriculum and students' standardized test scores are lower than those of their urban peers. Additionally, authors advocate for further analyses of the specific uses of technology in L2 classrooms, "including questioning how and for what pedagogical purposes it is being used."

The articles in this section raise many of the complex concerns related to colonizing forces; information flows, languages, and access; and the limits of technology itself in order to address the intricate and entwined social, political, and cultural issues that are always attendant in technological contexts. For instance, technology can be used to recolonize or to empower and promote languages and cultures, just as it can both disrupt global knowledge flows and support multilingual literacy or reinscribe dominant models of knowledge production and consumption. Ultimately, digital technology is only as empowering and transformative as the ability of users to access and engage with it in rich and critical ways that reach toward equity and social justice.

Many of these issues are taken up in the closing comments by Allan Luke, one of our keynote speakers at the conference, with a particular focus on ethics. In his paper, Luke argues that participation in digital culture entails many ethical considerations, particularly around access and the consequences of use. He argues that, among other forms of participation, 'users' should engage in critical examinations of the contents of digital archives - approaching them as representations of the world we live in-and calls for a renewed focus on civics and civility:

"It is not an adequate educational, philosophic, or political response to current cultural, geopolitical, and economic conditions and events for this generation of teachers, scholars, parents, caregivers, and community Elders to simply document or celebrate the emergence of new digital youth cultures without attempting to call out ethical parameters and concrete historical consequences for communities, cultures, and, indeed, human existence in this planetary ecosystem.”

Indeed, Luke calls for digital ethics to be at the center of curricula that include the examination of sources and ideologies as well as the relationships between forms of knowledge and global, planetary interests such as corporate ownership, capitalization, and profit from information more generally.

Taken together, the articles in this special issue tell stories of the ways in which digital technology can lead to damaging forms of exclusion and the reification of colonial relations, but as well as how it is possible to leverage new technologies toward more equitable spaces and societies. In our research and pedagogies going forward, we will want to more forcefully address the social distribution of digital access, examine diverse forms of engagement, and promote a more ethical framework for technology integration. In examining digital literacies through a more critical lens, educators and researchers can contribute to the construction of more equitable futures in the digital age. 


\section{Acknowledgements}

We would like to sincerely thank our outside reviewers for their important and thoughtful contributions to this special issue: Elise Chenier, Simon Fraser University; Rachel Heydon, Western University; Michelle Honeyford, University of Manitoba; Catherine Kell, University of Cape Town; Eva Lam, Northwestern University; Kimberly Lenters, University of Calgary; Onowa McIvor, University of Victoria; Mia Perry, University of Glasgow; Dianne Potts, Lancaster University; Claire Robson, Simon Fraser University. We would like to thank Caroline Hamilton and Yuya Takeda for their invaluable editorial and administrative assistance throughout this project.

This research was supported by the Social Sciences and Humanities Research

Council of Canada. Additional support was provided by the University of British

Columbia Office of Research and the Department of Language and Literacy Education.

\section{References}

Castells, M. (2010). The rise of the network society: The information age: Economy, society, and culture (Vol. 1). Malden, MA: Wiley and Blackwell.

Dobson, T., \& Willinsky, J. (2009). Digital literacy. In D. Olson \& N. Torrance (Eds.), The Cambridge handbook of literacy (pp. 286-312). Cambridge University Press.

First Call. (2017). 2017 BC Child Poverty Report Card. Retrieved from https://still1in5.ca/report-card/

Ito, M., Horst, H., Bittanti, M., boyd, d., Herr-Stephenson, B., Lange, P.G., Pascoe, C.J., \& Robinson, L. (2009). Living and learning with new media: Summary of findings from the digital youth project. Cambridge, MA: The MIT Press.

Knobel, M., \& Lankshear, C. (2006). Discussing new literacies. Language Arts, 84(1), 78-86.

Jenkins, H., Clinton, H., Purushotma, R. Robison, A., \& Weigel, M. (2009). Confronting the challenges of participatory culture: Media education for the $21^{\text {st }}$ century. Cambridge, MA: The MIT Press.

North, S., Snyder, I., \& Bulfin, S. (2008). Digital tastes: Social class and young people’s technology use. Information, Communication \& Society, 11(7), 895-911. DOI: 10.1080/13691180802109006

Rowsell, J., \& Pahl, K. (2007). Sedimented identities in texts: Instances of practice. Reading Research Quarterly, 42(3), 388-404.

Selwyn, N. (2017). Digital inclusion: Can we transform education through technology? Proceedings from X Conferencia Internacional Encuentros Barcelona 2016. Barcelona: Universidat de Barcelona.

Snyder, I., \& Prinsloo, M. (2007). Young people's engagement with digital literacies in marginal contexts in a globalised world. Language and Education, 21(3), 171179. DOI: $10.2167 / \mathrm{le} 745.0$

Warschauer, M. (2009). Digital literacy studies: Progress and prospects. In M. Baynham and M. Prinsloo (Eds.), The future of literacy studies (pp. 123-140). London, UK: Palgrave Macmillan.

Warschauer, M., \& Matuchniak, T. (2010). New technology and digital worlds: Analyzing evidence of equity in access, use, and outcomes. Review of Research in Education, 34(1), 179-225. 